\title{
"This one will delay us": barriers to accessing health care services among persons with disabilities in Malawi
}

\section{Alister C. Munthali, Leslie Swartz, Hasheem Mannan, Malcolm MacLachlan, Charles Chilimampunga \& Cecilia Makupe}

To cite this article: Alister C. Munthali, Leslie Swartz, Hasheem Mannan, Malcolm MacLachlan, Charles Chilimampunga \& Cecilia Makupe (2019) "This one will delay us": barriers to accessing health care services among persons with disabilities in Malawi, Disability and Rehabilitation, 41:6, 683-690, DOI: $10.1080 / 09638288.2017 .1404148$

To link to this article: https://doi.org/10.1080/09638288.2017.1404148

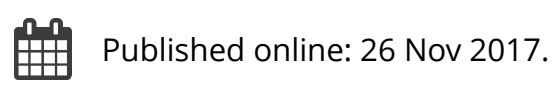

Submit your article to this journal $\pi$

Џll Article views: 446

Q View related articles $\sqsubset$

View Crossmark data $\longleftarrow$

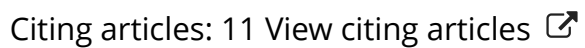




\title{
"This one will delay us": barriers to accessing health care services among persons with disabilities in Malawi
}

\author{
Alister C. Munthali ${ }^{\mathrm{a}}$ (D), Leslie Swartz ${ }^{\mathrm{b}}$ (D), Hasheem Mannan ${ }^{\mathrm{c}}$ (D), Malcolm MacLachlan ${ }^{\mathrm{d}, \mathrm{e}, \mathrm{f}}$ (D), \\ Charles Chilimampunga ${ }^{9}$ (D) and Cecilia Makupe ${ }^{\mathrm{h}}$ (D)
}

${ }^{a}$ Centre for Social Research, University of Malawi, Zomba, Malawi; ${ }^{b}$ Department of Psychology, Alan J Flisher Centre for Public Mental Health, Stellenbosch University, Stellenbosch, South Africa; 'School of Nursing, Midwifery and Health, University College Dublin, Dublin, Ireland; ${ }^{\mathrm{d}}$ Maynooth ALL (Assisting Living \& Learning) Institute and Department of Psychology, Maynooth University, Ireland; ${ }^{\mathrm{e} C e n t r e}$ for Rehabilitation

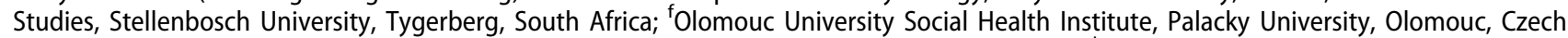

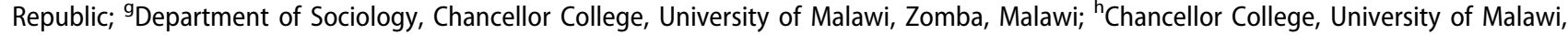
Zomba, Malawi

\section{ABSTRACT}

Purpose: This paper explores the barriers which people with disabilities experience in accessing health care services in Malawi.

Methodology: Fifty-two in-depth interviews were conducted with people with various types of disabilities. These interviews were conducted in four districts in Malawi: Blantyre and Phalombe in the Southern Region; Ntchisi in the Central Region, and Rumphi in the North. A team of trained research assistants conducted the interviews.

Results: The major challenges that people with disabilities experience include the cost of accessing health care, long distances to health facilities, lack of transport, hilly terrains and flooding of rivers during the rainy season, communication challenges with the health providers and poor attitude of health workers. Some of these challenges are not unique to people with disabilities, but constitute more of a problem among people with disabilities.

Conclusion: There is a need to address these challenges through the expansion of the provision of assistive devices, implementing comprehensive outreach services targeting people with disabilities and strengthening the links between key component of access to quality health care. Attitudinal barriers and lack of resources remain major challenges.

> IMPLICATIONS FOR REHABILITATION

- Though people with disabilities face challenges accessing health care world-wide, the challenges are greater in low-income countries. The current study in Malawi confirms this.

- Major challenges include costs of care, transport costs, and inaccessible facilities.

- Lack of health worker awareness and attitudinal barriers are major issues of concern.

- It is imperative, given this situation, that effort is spent in Malawi and similar contexts on dealing with issues of stigma and discrimination especially in the health care sector.

- It is also important to explore cost-effective ways of assisting people with disabilities accessing appropriate transport, which should be seen as part of the healthcare system.

- Though the cost of providing equitable care may be high in low-income contexts, this is a human right. Training and creating an accessible and disability-friendly service environment is a key priority.

\section{Introduction}

While the Constitution of the Republic of Malawi assures Malawians that the state shall "provide adequate health care, commensurate with the health needs of Malawian society and international standards of health" [1, para.13.3], there exist barriers to accessing health care. These barriers include the critical shortage of medicines in health facilities, long waiting times, negative attitudes of health workers, the cost of health care and long distances to health facilities [2]. Most of these challenges have also been highlighted in Malawi's Health Sector Strategic Plan 2011-2016 [3]. These challenges are not unique to Malawi, as other developing countries experience similar challenges [4-11]. While a number of studies examine barriers to accessing health
ARTICLE HISTORY

Received 6 January 2017

Revised 8 November 2017

Accepted 8 November 2017

\section{KEYWORDS}

Malawi; disability; health care; barriers; discrimination care in the general population $[3,12]$, not as much is known about accessing health care for people with disabilities in Malawi.

As is the case in other countries, people with disabilities in Malawi have been shown to experience poor health and education outcomes relative to the general population [13-15]. People with disabilities also experience challenges in accessing social and health services. For example, a large-scale study found that, although $84 \%$ of people with disabilities were aware of health services available in the areas where they lived and that $83 \%$ required these health services, only $64 \%$ of those who needed services actually received them [15]. This finding is in keeping with similar studies conducted in other Southern African countries [16-18]. Although the challenges people with disabilities face in 
Malawi are well known, there is little information available on how the challenges in accessing services are experienced by the people themselves. If changes are made and services planned without input from service users themselves, there is a strong possibility that they will not address service users' needs and concerns. For this reason, this article bridges this gap in knowledge.

\section{Background - the delivery of health services in Malawi}

The bulk of health services in Malawi are provided by the Ministry of Health, with the Christian Health Association of Malawi (CHAM) being the second biggest provider; together they provide $97 \%$ of the health services [19]. Other health service providers include private-for-profit providers and companies. CHAM is a major partner of the Ministry of Health in the delivery of health services with most of its health facilities located in rural areas. The catchment areas of the Ministry of Health and CHAM health facilities do not overlap. The policy of the Ministry of Health is that Malawians should live within a radius of $8 \mathrm{~km}$ of a health facility. In 2015, $23.1 \%$ of Malawi's population was residing outside this recommended radius, which implies that there is a shortage of health facilities in the country [20]. The delivery of health services in public health facilities is free of charge. However, CHAM charges user fees. The Government of Malawi has established service level agreements (SLAs) with selected CHAM facilities which enable Malawians to access certain health services in CHAM facilities free of charge, with an emphasis on maternal, neonatal and child health services [3]. The rationale for the establishment of service level agreements is that cost should not be a barrier to accessing health services.

Health services in Malawi are delivered at three levels, namely the primary, secondary and tertiary levels and these levels are interlinked through a comprehensive referral system. The delivery of health services is severely hampered by the shortage of health workers: in 2014/15, 52\% of the established positions in the Ministry of Health were vacant, with vacancy rates among medical specialists and nurses at $86 \%$ and $74 \%$, respectively. This is exacerbated by the maldistribution of health workers, with most of them allocated to urban facilities compared to rural communities where more than $80 \%$ of the Malawi population reside [21]. The delivery of health services is also hampered by a shortage of funding: the per capita total health expenditure is estimated at US\$39, which is grossly inadequate for the effective delivery of health services to Malawians [22].

Existing policies and practices do not adequately address the needs of people with disability. People with disabilities experience major challenges [23]. It is crucial to know more about how access issues are experienced and understood by the people most affected by them. This is a question not only of recognition of the rights of people with disability in terms of global disability rights as enshrined in instruments such as the UN Convention on the Rights of Persons with Disabilities (UNCRPD) [24] but also a matter of good service planning. Contemporary thinking on health systems planning suggests that user knowledge and input is very important, but frequently overlooked as a crucial source of data [25-27].

The work presented here forms part of the Equitable Access to Health Care among Vulnerable Populations (EquitAble) Project. The overall aim of the EquitAble Project was to explore the availability and accessibility of health care services among vulnerable population groups, including people with disabilities in Malawi, Namibia, South Africa and Sudan. Full details of the project and the teams involved can be found at www.equitableproject.org. The project has explored the extent to which health and related policies internationally, regionally, and in the target countries, were inclusive of vulnerable groups, including people with disabilities [24], has provided information on health care utilization in the target countries $[23,28-30]$, and has shown through large scale surveys in 17 sites across four countries that access of people with disabilities to health care is a serious challenge [31].

\section{Methodology}

\section{Research setting and context of the study}

Malawi is divided into three regions, namely the northern, central and southern regions. There are four major ethnic groups, these being the Chewa who are found in central Malawi, the Yao and the Lomwe in the south and the Tumbuka who are found in the north. Three ethnic groups were represented, excluding the Yao ethnic group, because a large study on access to health care had just been conducted among this group a few years earlier [32,33]. Data collection for the EquitAble Project was done in four districts in Malawi, namely Blantyre and Phalombe in the Southern Region; Ntchisi in the Central Region; and Rumphi in the Northern Region. Ntchisi District is mainly inhabited by the Chewa people, Phalombe by the Lomwes, while the Tumbukas are predominantly in Rumphi. Blantyre was selected as the site for the study because, being an urban area, problems related to accessing health care would be different from those occurring in rural areas. Twelve research assistants (RAs) were employed and trained for one week by members of the Consortium. The training of the RAs and close supervision of the data collection process, including an analysis of the transcripts, ensured that data of high quality were collected. The additional use of experienced RAs in this study also contributed to ensuring high data quality. The data for this study were collected in 2010.

The point of entry for this study in each of the four districts was the District Health Officer (DHO). The purpose of the study was explained to the $\mathrm{DHO}$ who was requested to help the research team to identify two health facilities: one which belonged to CHAM and the other to the Ministry of Health. Eight health facilities were selected with the help of the District Health Officers. Data were collected in the catchment areas of selected health facilities.

A total of 244 in-depth interviews were conducted in this phase of the study: 81 in Blantyre, 63 in Phalombe, 50 in Ntchisi and another 50 in Rumphi. More interviews were done with females (142) than males (102). Interviews were done with a wide range of informants, namely users of health services, non-users of health services and providers of health services. Out of the 244 interviews, 52 interviews were conducted with people with various types of disabilities. Snowballing was used to identify people with disabilities as well as non-users of health services, as many nonusers were existent in the communities which were visited. The interviews with people with disabilities were face to face interviews and explored various issues, including the barriers which they experience in accessing health services. This paper analyses interviews which were conducted with people with disabilities, and explores the barriers they experienced in accessing health services.

\section{Data analysis}

The in-depth interviews with people with disabilities were recorded and transcribed. The major themes and sub-themes were identified by the members of the research team, based on 
the issues which emerged from the data. The analysis of the data collected in this study was aided by the use of NVIVO into which all the transcripts were imported and coded. The data were analysed using thematic analysis [34] and organised according to the approach posited by Mudrick and Yee [35] who suggest that a useful way of categorising access challenges to health care by people with disabilities is by grouping them under the headings of financial, structural and programmatic. They define structural barriers as those related to architectural characteristics of medical offices such as the width of the doors and availability of stairs and lumps. Programmatic access to health care encompasses policies and practices which constitute part of the health care delivery system which may have an impact on the ability of patients with disabilities to receive the same quality of health care as everyone else. These programmatic access issues include methods of communicating with people with disabilities and the treatment of patients with disabilities by medical personnel. Financial barriers have been defined as those related to coverage limitations for various forms of treatment, medical equipment and referrals to medical specialists [35]. This implies that financial barriers relate both to the individuals as well as to providers of health care services.

\section{Ethical considerations}

The protocol for this study was submitted to the National Health Sciences Research Committee (NHSRC) whose secretariat is in the Ministry of Health in Malawi. The NHSRC is the institutional review board which reviews all protocols on health and related fields. This study was implemented after receiving approval from the NHSRC. None of the participants were forced to participate in this study and consent was obtained from all study participants. This was largely oral consent because of high illiteracy rates.

\section{Results}

Table 1 provides a description of the participants interviewed for this study. In line with the Mudrick and Yee [35] typology, results are presented under each of the major headings in turn.

Table 1. Characteristics of informants.

\begin{tabular}{lcr}
\hline Age & Number of participants & Percentage \\
\hline Less than 20 & 8 & 15.4 \\
$21-34$ & 8 & 15.4 \\
$35-49$ & 5 & 9.6 \\
$50-64$ & 7 & 13.5 \\
$65-79$ & 15 & 28.8 \\
$80+$ & 5 & 9.6 \\
Unknown & 4 & 7.7 \\
Sex & & \\
Male & 25 & 48.1 \\
Female & 27 & 51.9 \\
Type of disability & & \\
Physical & 22 & 42.3 \\
Epilepsy & 6 & 11.5 \\
Visual & 12 & 23.1 \\
Hearing & 6 & 11.5 \\
Mental & 6 & 11.5 \\
Level of education & & \\
None & 18 & 34.6 \\
Primary & 27 & 51.9 \\
Secondary & 1 & 1.9 \\
Secondary+ & 1 & 1.9 \\
Not specified & 52 & 9.6 \\
& 52 & 100.0 \\
\hline
\end{tabular}

\section{Financial barriers}

\section{Cost of accessing health services}

Many people with disabilities said that they do not access health care because the nearest health facility in their communities belonged to CHAM, which charges user fees. They explained that they were poor, hence they could not afford to pay for services:

The lack of money is another major factor that affects people's access to the health care. Because when one has no money that means he cannot access health care because the facility in the area is a CHAM facility they don't offer free services. (Male informant, aged 64-79, deaf and blind, Blantyre).

An elderly female informant in Blantyre explained that it is not only people with disabilities who fail to access health care from CHAM facilities; in her community, many people with or without disabilities are poor and they cannot afford to pay user fees at CHAM facilities. Some people with disabilities, especially the elderly, said they stopped going to CHAM facilities because they do not have any source of income. Some informants reported that, in CHAM facilities, a patient is only given prescribed drugs equivalent to the amount of money they are able to pay. A number of participants would have liked to have attended private clinics, as care was perceived to be better there, but they could not afford the fees. A major difference reported between private and public facilities was that private facilities have adequate medicines and are not subject to stock outages.

The inability to pay for accessible transport to facilities was a common problem, especially where long distances needed to be travelled. Long waiting times at facilities also left participants hungry and thirsty and many did not have funds to buy food and drink while waiting. The issues of costs, therefore, go far beyond the question of payment for treatment. Strategies used by some participants to pay for health care access included selling their harvests, chickens, or other livestock, earning small amounts of money through running small scale businesses and doing piece work in other people's gardens. The extent to which this was possible was, of course, partly dependant on the nature of impairments and also on health status. A small number of elderly people with disabilities reported that they were able to pay for health services at CHAM facilities because they have children who are responsible for paying the bills when they are unwell, but most participants come from financially stretched families with meagre funds to go around.

\section{Structural barriers to accessing health services}

In addition to architectural design features of health facilities, such as lack of ramps and elevators, as identified by Mudrick and Lee [35], Goins et al. [36] add that structural barriers are inherent in the service delivery system and the environment itself which, among others, includes transportation difficulties, a limited health care supply and lack of quality health care. In the present study, people with disabilities identified a number of structural barriers that they experienced in seeking health care.

\section{Long distances to health facilities}

There were people with disabilities who lived very close to the health facilities and did not have any problems in terms of getting to the facility during illness episodes. However, others were resident very far from health facilities and these reported that 
distances to health facilities were long and this was a major barrier to accessing health services:

I cannot walk to the health facility to access the health care because of my disability since it is very far from my home. Nobody takes me there either. My husband is also disabled and we are both helpless. (Woman with physical disability, aged 50-64, Ntchisi)

This woman stayed $9 \mathrm{~km}$ from the nearest health facility. Some informants with disabilities, especially the elderly, reported that they stopped accessing health services they needed altogether because of the long distances: old men and women were unable to walk long distances either because they had a disability or suffered pain. For example, a man in his $80 \mathrm{~s}$ with a disability, living in Blantyre, reported that he stopped accessing health services because the nearest health facility for him was 18 kilometres away; it was difficult for him to walk such a distance. This was exacerbated by the lack of a reliable public transportation system in his community. Transport was also a problem for people with visual impairments, sometimes together with other impairments:

On my own I cannot walk to the health facility because I cannot see and I have rheumatism. My children cannot carry me on a bicycle because I have dizziness whenever I am put on the bicycle, so this makes me not access formal health care services. (Woman with visual impairment, aged 65-79, Ntchisi)

The lack of public transport was also mentioned in other districts such as Rumphi where the road network was not good. People with disabilities were also asked if health facilities ever provide transport to the health facilities for people who are sick. In general, informants reported that the health centres do not provide transport for patients, including patients with disabilities, to get to health centres except during referral of cases of serious illness to higher level health facilities. They explained that when a health centre is referring a patient to the District Hospital, health centre staff will call for an ambulance. This is the only time when transport is provided. Ambulances in this context are provided free of charge. The ambulances are not provided to collect patients from their homes to take them to primary health care facilities. While this is the case, in some communities, however, there are motorbike ambulances which are helpful in terms of transporting patients from the community to a health facility. For example, an informant said that community members can request a motorbike ambulance when there is a need:

The facility assists with transport sometimes when people from the community go and report that someone is very sick such that they cannot take him to the facility on foot. There is a motorbike ambulance which goes to the community to ferry patients who are seriously ill.

(Woman, young adult with a physical disability, Ntchisi)

People with disabilities residing close to health facilities were in general happy with the location of health facilities. All those who reported not being happy with the location of the health facility lived far from facilities.

\section{Hilly terrains and flooding of rivers}

In one catchment area of a health facility in Blantyre, and another in Rumphi, the terrain was quite hilly and people with disabilities and the elderly said that it was difficult, if not impossible, for them to walk over such hilly terrains, especially if the distances were quite long. In some places in Blantyre the hilly terrain is also exacerbated by the general lack of public transport in the area hence making it difficult for people with disability. Some of the roads, especially in rural Blantyre and Rumphi, are also in a bad state - even bicycles and vehicles cannot pass. The hilly terrain has meant that some people fail to access health care: an elderly woman with a disability in Blantyre said that she was not using formal health care services because she is very old and cannot walk in these hilly places:

The main problem I think can affect a person accessing health care is difficulties in walking. People with disabilities have problems in walking and the place itself is hilly and the distance itself is very long - this makes people with disabilities not to access health care. (A 79-year-old woman with physical disability, Blantyre)

For older participants in particular, arthritis commonly made walking difficult. In one catchment area in Blantyre, even though the bicycles and bicycle taxis are available, informants said that these cannot be used to carry patients because the terrain is so hilly. In some cases, the flooding of rivers tends to result in people with disabilities' failure to access health services: for example, a young woman in Blantyre who was physically disabled said that there are two rivers between her community and the nearest health facility. There are no proper bridges over these rivers. During the rainy season, these rivers flood, making it difficult for people with disabilities, like herself, to access health services.

\section{Lack of an assistant to accompany a person with a disability to health facilities}

People with mobility impairments were reliant on others either to carry them on their backs to facilities, or to transport them by bicycle, where possible. Those with visual impairments needed someone to lead them, especially across treacherous terrain. For example, a visually impaired woman in Blantyre district said that when going to the health facility she goes with a child who leads the way.

In the absence of formal help, though, it is not always possible for a community member to assist. The mother of a young man with a mental health problem reported that when he is actively ill he becomes violent and will beat her if she tries to take him to the hospital. She therefore leaves him untreated. She is too old and weak to carry him forcibly to the hospital; community members are not willing to assist because of fear and stigma. Not all families are supportive. For example, a physically disabled elderly woman in Blantyre district said she has problems accessing health services and, in fact, she does not go there at all:

Relatives leave me in the house when sick, failing to send me to the health facility. (64-79-year-old woman with physical disability and unable to walk, Blantyre)

She explained that her relatives leave her in the house whenever she is sick, and she is not in a position to hire a bicycle to take her to the hospital because she has no money. She explained that she would have needed to be carried to the health facility by relatives; as they were not available she could not access care.

\section{Language and communication problems}

For some people with disabilities, especially those who are deaf, it is difficult for them to communicate effectively with health care personnel. There are no sign language interpreters. Sometimes health care personnel are impatient where there are communication challenges. For example, a 42-year-old woman in Blantyre, who was deaf, reported that doctors always ignored her, saying "atichedwetsa awa" (which literally means that "this one will delay us"). In addition, people who have hearing and speech impairment may have their privacy and confidentiality breached by the presence of a third party. The 42-year-old woman referred to above relies on her sister to accompany her to interpret, but she would prefer not to reveal private matters regarding her health to 
her sister. Without her sister's help, however, she cannot access health care at all - a year previously she had gone to a health facility alone and had to leave without treatment because the staff could not communicate with her. She experiences similar problems with the local community health worker, who cannot assist her due to communication barriers.

There were a few people with hearing impairments who had accessed hearing aids. A 70-year-old man in Blantyre said he can hear only by making use of a hearing device which would be difficult for others who do not have one:

Difficult communication also affects my health care access. For example, I can only hear by the use of a hearing device but when one does not have the device and no guardian, it will be very difficult to communicate with the health workers. They may speak to him but he may not get what they are saying. (A 70-year-old man with hearing impairment, Blantyre)

A major challenge for those provided with hearing aids is the cost of batteries and the cost of maintenance of the aids - without ongoing support, the devices may become unusable.

\section{Programmatic barriers}

\section{Providers' attitudes}

The majority of the people with disabilities said that the health workers treated them quite well. There were others, however, who complained about poor attitudes of health workers as a major barrier for accessing health services. Some people with disabilities said that some health workers are harsh and rude and they shout at patients, even favouring their own friends and relatives when providing services. Prejudice and discrimination also play a part:

I have experienced a lot of things. For example, my own disabled daughter has schizophrenia. She was sick so I took her to the hospital for treatment. Unfortunately, I was chased away by the health workers and was told that they don't keep mentally ill patients at their facility and if I wanted I should go to Zomba [Mental] Hospital where they keep these kind of patients... (A 50-64-year-old woman with a child who has schizophrenia, Phalombe)

The refusal to treat a person with a serious mental disorder is against policy. Since this patient did not get any treatment, her mother then reluctantly took her to a local herbalist for help. This is just one example of many reports of people with disabilities not being treated well or not receiving treatment at all.

Provider attitudinal and work practice issues affect all community members. Some health workers refuse to attend to patients at night or on a holiday despite a commitment in policy to providing emergency care round the clock. One female informant with a disability in Ntchisi gave an example of her son who became ill on a Sunday. She took him to the health facility and he was told that the facility does not operate on Sundays, even in emergencies. She had to buy medication from a local shop. She was anxious that the medication, which was sold by someone with no health care or pharmaceutical training, might be ineffective or harmful.

\section{Long queues at the health facilities}

Long queues tend to discourage people with disabilities from accessing health services. Though this also applies to those without disabilities, the challenges of queuing when one has a physical impairment or when one experiences pain, may be greater. A young woman in Ntchisi said that sometimes a patient loses patience when waiting for their turn to come and could decide to go back home to seek alternative health care services. Relatives and friends who assist people with disabilities may also influence patients, including patients with disabilities, to give up on the queue and go home - these people are offering help but may become tired of having to wait with the patient.

Some facilities do try to take waiting times into account when dealing with patients with disabilities, but this is clearly dependant on who the staff happen to be. Preferential treatment may cause its own problems, though. One informant with a disability said that at one time she went to the health facility and got instruction from one of the members of staff to see the medical assistant straight away without queueing. Other patients thought that they had been taken advantage of. They thought it was not right for someone to be treated without being in the queue. This raises the issue not only of staff attitudes but also of the attitudes of other patients. A participant with a physical disability reported that other patients assume that because of her physical disability she must have a mental disorder as well. She is stigmatised and shunned while waiting for care, as she does not feel comfortable to be with others who stigmatise her, calling her "mad".

\section{Other factors that may affect access to health services by people with disabilities}

In addition to the factors outlined above, there were others which were also mentioned by people with disabilities as contributing to the creation of barriers to accessing health services. As mentioned above, some of these factors affect the general population as well. For example, beliefs in witchcraft as a cause of disease and illness still prevail amongst Malawians and many people believe that such diseases cannot be easily diagnosed and effectively treated by clinicians in health facilities. A guardian of a woman with a disability said that some people find it more difficult to access health care because witchcraft causes the diseases they suffer from. When such people visit a health facility the clinicians fail to diagnose the health problems that they suffer from and they will opt to seek care from traditional healers.

Other people with disabilities, just like those without disabilities, believe in the efficacy of traditional medicines. A man with a disability in Rumphi, said that others do not go to health facilities during illness episodes because they rely on traditional medicines, and whenever they are sick they just go into the bush to get herbs or they go to herbalists who give them the traditional medicines. He gave an example of diseases such as pneumonia, infertility and body pains which are perceived to be cured easily by herbalists. In some cases, access to health services can be made more difficult because of religious reasons. A number of informant mentioned that one of the major problems in terms of people accessing health care, including people with disabilities, is membership of religious organisations which prohibit their members from accessing health services. Prominent amongst these religious groups forbidding use of health services were Church of God, the Zion Church and Jehovah Witnesses [37].

\section{Discussion}

This study has demonstrated that people with disabilities experience a wide range of barriers in accessing health services. One of the most important barriers is the cost of accessing health services. Poverty in Malawi is widespread: $50.7 \%$ of the population live below the poverty line [38]. It is not only people with disabilities who experience challenges in paying for services at health facilities belonging to CHAM but people without disabilities as well. Other studies have shown that the cost of health care is more likely to be a barrier for people with disabilities compared to those without a disability; people with disabilities are 
economically disadvantaged and less likely to be employed [39]. Though some participants use traditional medicine because of their belief system, we encountered those who did so because they could not afford biomedical care. Poverty is one driver for reliance on non-traditional approaches such as indigenous paraprofessionals, especially in rural areas [40].

Issues of distance, transport challenges and the challenges of long waiting times have been identified in previous work in Malawi and in neighbouring countries [23,30]. Mudrick and Yee [34] argue that there is a need to put in place policies which enable people with disabilities "who may not be able to tolerate waiting for extended periods in a reception area to be seen upon arrival". This is difficult to implement in a context in which both health care providers and other patients, as our data show, may hold discriminatory attitudes and may object to what they perceive as preferential treatment for people with disabilities. Clearly one of the key issues underlying many of the challenges faced by participants is the issue of attitudes, and lack of appreciation of the difficulties associated with negotiating a complex environment with little support [29].

Some of the challenges experienced by people with disabilities may be addressed if they are provided with assistive devices. In this study, there was one informant who had a hearing aid and he noted that having this device helped him significantly in addressing communication barriers. While the Government of Malawi, with support from development partners, has tried to provide assistive devices such as wheelchairs and crutches to people with disabilities, it remains the case that many who need these devices do not have access to them or to the help they need in utilizing the devices optimally. A 2003 study found that while 69\% of people with disabilities in Malawi needed assistive device services, only $5 \%$ received them [15]. The World Health Organization's GATE (Global Collaboration on Assistive Technology) program provides both a challenge and an opportunity for the government of Malawi to implement the provision of the Assistive Product List (APL) of 50 priority products through the development of a crosssectoral systemic approach [41].

One of the major findings from our research is the need to adopt a systems approach to providing health care for people with disabilities. Whether this is in terms of providing transport to clinics, ensuring that people have the finances and opportunity to buy batteries for hearing aids, or that health care providers are able and willing to engage with people with disabilities in an equitable way compared to other services users, there is a need for more collaborative systems thinking that reflects the realities and complexities of care pathways for people with disabilities. However, more than this, the experience that people with disabilities have of health systems may constitute an excellent overall probe of the accessibility and appropriateness of the broader health system; allowing other users to also benefit from improved access and enhanced systems thinking [42].

\section{Conclusions}

Many of the challenges experienced by people with disabilities, as detailed in this paper, affect both people with disabilities and those without. Issues which are common in the community - such as poverty, lack of transport, stock outages and attitudinal barriers - are magnified both in the context of practical challenges many people with disabilities face and in the context of stigma and discrimination. Barriers do not exist in isolation - they are complex and intersecting, and operate at multiple levels for people leading difficult and challenging lives. For this reason, the health service experiences of people with disabilities may constitute an excellent probe for evaluating the over-all accessibility and quality of health systems. There are similarities between the issues faced by our participants and those reported by studies in wealthy countries, but the burdens are greater. For example, in many contexts, even in wealthy countries, people with disabilities face challenges of inaccessible buildings and transport; in Malawi, as in other poor countries, these challenges may translate into the reality of having to be carried for long distances on a relative's back, with all the pain and indignity that this may imply for both parties. The fact that some of our participants had effectively given up trying to access health care is especially worrying, but understandable in light of the magnitude and range of intersecting challenges faced.

Some of the challenges can be addressed through comprehensive outreach services as well as expanding the provision of assistive devices. The current outreach services, as delivered by Ministry of Health and other stakeholders, are limited and do not reach everyone, nor do they necessarily reach across sectors. This has implications for health and even for survival. More work needs to be done in exploring low cost, contextually appropriate services and devices and the APL constitutes an important initiative in this respect. The stories we have heard are often stories of resilience and survival under harsh conditions and it is essential that the voices of those who experience the visceral and bodily consequences of exclusion and lack of access form a key part of developing new policies, and where they exist, in implementing commitments for equitable access and quality services in existing policies

\section{Acknowledgements}

We thank Jacqueline Gamble for editorial assistance.

\section{Disclosure statement}

No potential conflict of interest was reported by the authors.

\section{Funding}

This research was funded by the European Commission Framework Programme 7: "Enabling Universal and Equitable Access to Healthcare for Vulnerable People in Resource Poor Settings in Africa" (Grant Agreement No. 223501).

This work is also based on research supported in part by the National Research Foundation of South Africa (Grant specific unique reference number (UID) 85423). The Grantholder (LS) acknowledges that opinions, findings and conclusions or recommendations expressed in any publication generated by the NRF supported research are that of the authors, and that the NRF accepts no liability whatsoever in this regard.

\section{ORCID}

Alister C. Munthali (D) http://orcid.org/0000-0002-3495-3446

Leslie Swartz (iD http://orcid.org/0000-0003-1741-5897

Hasheem Mannan (D) http://orcid.org/0000-0001-6209-2586

Malcolm MacLachlan (iD http://orcid.org/0000-0001-6672-9206

Charles Chilimampunga iD http://orcid.org/0000-0001-8835-314X

Cecilia Makupe (D) http://orcid.org/0000-0002-6060-8662

\section{References}

[1] Government of Malawi. Constitution of the Government of Malawi; 1994. [cited 2017 July 6]. Available from: http:// 
publicofficialsfinancialdisclosure.worldbank.org/sites/fdl/ files/assets/law-library-files/Malawi_Constitution_1994_ (as\%20amended)_en.pdf.

[2] Lungu EA, Biesma R, Chirwa $M$, et al. Health care seeking practices and barriers to accessing under-five child health services in urban slums in Malawi: a qualitative study. BMC Health Serv Res. 2016;16:410. doi: 10.1186/s12913-0161678-x.

[3] Ministry of Health. Health sector strategic plan 2011-2016. Lilongwe: Ministry of Health; 2011 [cited 2017 July 6]. Available from: http://www.nationalplanningcycles.org/sites/ default/files/country_docs/Malawi/2_malawi_hssp_2011_2016_final_document_1.pdf

[4] Government of Zambia. National health strategic plan 2011-2015. Lusaka: Ministry of Health; 2011.

[5] Government of Lesotho. Health sector strategic plan 2012/ 13-2016/17. Maseru: Government of Lesotho; 2013 [cited 2017 July 6]. Available from: http://www.nationalplanningcycles.org/sites/default/files/country_docs/Lesotho/19_04_ 2013_lesotho_hssp.pdf.

[6] Government of Kenya. Health sector strategic and investment plan 2013-2017. Nairobi: Government of Kenya [cited 2017 July 6]. Available from: http://www.who.int/pmnch/ media/events/2013/kenya_hssp.pdf.

[7] Ensor T, Cooper S. Overcoming barriers to health services access: influencing the demand side. Health Policy Plan. 2004;19:69-79.

[8] Kizito JM, Kayendeke C, Nabirye SG, et al. Improving access to health care for malaria in Africa: a review of literature on what attracts patients. Malar J. 2012;11:15. doi: 10.1186/ 1475-2875-1155.

[9] Atwine F, Hultsjo S, Albin B, et al. Health care seeking behaviour and use of traditional medicine among persons with type 2 diabetes in South-Western Uganda: a study of focus group interviews. Pan Afr Med J. 2014;20. doi: 10.11604/pamj.2015.20.76.5497.

[10] Schwitters A, Lederer P, Ziversmit L, et al. Barriers to health care in rural Mozambique: a rapid ethnographic assessment of planned mobile health clinics for ART. Glob Health Sci Pract. 2015;3:109-116.

[11] O'Donnel O. Access to health care in developing countries: breaking down demand side barriers. Cad Saude Publica. 2007;23:2820-2833.

[12] Kalungwe P. Evaluating the impact of non-user-fee maternal and neonatal health services programme in reducing maternal and neonatal mortality in Nkhotakota District, Malawi. Blantyre, Malawi: College of Medicine, University of Malawi; 2009.

[13] Mitra S, Posarac A, Brandon V. Disability and poverty in developing countries: a snapshot from the World Health Survey. Washington: The World Bank; 2011.

[14] Graham L, Moodley J, Ismail Z, et al. Poverty and disability in South Africa. Johannesburg: Centre for Social Development in Africa and University of Johannesburg; 2014.

[15] Loeb M, Eide AH. Living conditions among people with activity limitations in Malawi. Oslo: SINTEF; 2004.

[16] Eide $A H$, Ingstad B. Disability and poverty - reflections on research experiences in Africa and beyond. Afr J Disabil. 2013;2:31. [cited 2017 July 6]. Available from: http://dx.doi. org/10.4102/ajod.v2i1.31.

[17] Eide $\mathrm{AH}$, Loeb M. Living conditions of persons with activity limitation in Zambia. Oslo: SINTEF; 2006.
[18] Kamaleri $\mathrm{Y}$, Eide $\mathrm{AH}$. Living conditions among people with disabilities in Lesotho. Oslo: SINTEF; 2011.

[19] Ministry of Health. Human resources for health strategic plan 2012-2014. Lilongwe: Ministry of Health; 2012.

[20] Ministry of Health. Situation analysis of the health sector. Lilongwe: Ministry of Health; 2015.

[21] Ministry of Health. 2014/2015 annual review report for the health sector. Lilongwe: Ministry of Health; 2015.

[22] Ministry of Health. Situation of the health sector. Lilongwe: Ministry of Health; 2015.

[23] Munthali AC, Makupe CM. Exploring access to and delivery of health care services in Malawi. Zomba: Centre for Social Research; 2011.

[24] McVeigh J, MacLachlan M, Gilmore B, et al. Promoting good policy for leadership and governance of health related rehabilitation: a realist synthesis. Global Health. 2016;12:49. doi: 10.1186/s12992-016-0182-8.

[25] Gilson L, Barasa E, Nxumalo N, et al. Everyday resilience in district health systems: emerging insights from the front lines in Kenya and South Africa. BMJ Glob Health. 2017;2: e000224. doi: 10.1136/bmjgh-2016-000224.

[26] Rashid A, Thomas V, Shaw T, et al. Patient and public involvement in the development of healthcare guidance: an overview of current methods and future challenges. Patient. 2017;10:277. https://doi.org/10.1007/s40271-016-0206-8.

[27] Amin M, MacLachlan M, Mannan H, et al. EquiFrame: a framework for analysis of the inclusion of human rights and vulnerable groups in health policies. Health Hum Rights. 2011;13:1-20.

[28] Badri B, Amin M, Gamal ElDeen A, et al. Enabling universal and equitable access to healthcare for vulnerable people in resource poor settings in Africa. Khartoum: Ahfad University; 2011.

[29] Vergunst R, Swartz L, Mji G, et al. 'You must carry your wheelchair' - barriers to accessing healthcare in a South African rural area. Glob Health Action. 2015;8:29003. doi: 10.3402/gha.v8.29003

[30] Van Rooy G, Amadhila EM, Mufune P, et al. Perceived barriers to accessing health services among people with disabilities in rural northern Namibia. Disabil Soc. 2012;27:761-775.

[31] Eide $A H$, Mannan $H$, Khogali $M$, et al. Perceived barriers for accessing health services among individuals with disability in four African Countries. PLoS One. 2015;10:e0125915. doi: 10.1371/journal.pone.0125915.

[32] Braathen SH, Munthali A, Grut L. Explanatory models for disability: perspectives of health providers working in Malawi. Disabil Soc. 2015;30:1382-1396.

[33] Munthali AC, Braathen SH, Grut L, et al. Seeking care for epilepsy and its impacts on households in a rural district in southern Malawi. Afr J Disabil. 2013;2:54. doi: 10.4102/ ajod.v2i1.54.

[34] Hsieh H, Shannon SE. Three approaches to qualitative content analysis. Qual Health Res. 2005;15:1277-1288.

[35] Mudrick NR, Yee S. Defining programmatic access to healthcare for people with disabilities. Berkeley (CA): Disability Rights Education and Defense Fund; 2007.

[36] Goins RT, Williams KA, Carter MW, et al. Perceived barriers to health care access among rural older adults: a qualitative study. J Rural Health. 2005;21:206-213.

[37] Munthali AC, Mannan H, MacLachlan M, et al. Seeking biomedical and traditional treatment is a spiritual lapse among Zionists: a case study of the Zion Church in Malawi. Ufahamu: A Journal of African Studies. 
[38] National Statistical Office. Integrated household survey 2010-2011. Zomba: National Statistical Office; 2012.

[39] McColl MA, Jarzynowska A. Shortt SED. Unmet health care needs of people with disabilities: Population level evidence. Disabil Soc. 2010;25:205-218.

[40] Leishmer DM, Richardson M, Levine $P$, et al. Access to primary health care among persons with disabilities in rural areas: a summary of literature. J Rural Health. 1996; 12:45-53.

[41] Khasnabis C, Mirza Z, MacLachlan M. Opening the GATE to inclusion for people with disabilities. Lancet. 2015;386:2229-2230.

[42] MacLachlan M, Mannan H, McAuliffe E. Access to healthcare of persons with disabilities as an indicator of equity in health systems. Open Med. 2011;5:414. 